\title{
A rare case of subacute uterine inversion managed by Haultain's repair
}

\author{
Maruti Sinha $^{1}$, Ridhima Gupta $^{2} *$, Pushpender Gupta ${ }^{3}$, Aruna Tiwari $^{1}$ \\ ${ }^{1}$ Department of Obstetrics and Gynecology, Kasturba Hospital, Jama Masjid, New Delhi-110002, India
${ }^{2}$ Department of Obstetrics and Gynecology, Lutheran Medical Center, Brooklyn, New York, USA, 11220
${ }^{3}$ Department of Obstetrics and Gynecology, Wake Forest School of Medicine, Winston Salem, North Carolina, USA,
27157
}

Received: 22 April 2013

Accepted: 10 May 2013

*Correspondence:

Dr. Gupta R,

E-mail: ridhimagupta.04@gmail.com, rgupta2@1mcmc.com

(C) 2013 Sinha M et al. This is an open-access article distributed under the terms of the Creative Commons Attribution Non-Commercial License, which permits unrestricted non-commercial use, distribution, and reproduction in any medium, provided the original work is properly cited.

\section{ABSTRACT}

Uterine inversion is a rare but serious obstetrical emergency which usually occurs due to mismanagement of third stage of labour. If the condition is promptly recognized before incarceration, manual repositioning of the uterus may be successful. However in neglected uterine inversion, incarceration may occur due to constriction ring formation, necessitating surgical intervention. We present a case of neglected uterine inversion managed by Haultain`s repair.

Keywords: Uterine inversion, Haultain's repair

\section{INTRODUCTION}

Uterine inversion is a rare but serious obstetrical emergency which usually occurs due to mismanagement of third stage of labour. If the condition is promptly recognized before incarceration, manual repositioning of the uterus may be successful. However in neglected uterine inversion, incarceration may occur due to constriction ring formation, necessitating surgical intervention. We present a case of neglected uterine inversion managed by Haultain`s repair.

\section{CASE REPORT}

A 30 years old para 2 female, presented with complaint of mass protruding out of vagina for past one day on postpartum day three. The patient delivered a healthy male baby at full term per vaginally. The delivery was conducted by traditional birth attendant. There was prolonged third stage of labor. The traditional birth attendant removed the placenta after approximately 2 hours by cord traction. The patient was not aware of any complication at the time of removal of the placenta. Patient had severe post partum hemorrhage associated with mild abdominal pain approximately 6 hours after placental removal which continued overnight. She could not reach the hospital emergency on the same day due to lack of attendant and transport. Forty eight hours after deliver the patient noticed a mass protruding out of vagina during micturition. In the hospital emergency, patient was hypotensive (BP 90/60, pulse 120/minute, Temp. $\left.99.6^{\circ} \mathrm{F}\right)$. Local examination confirmed a soft reddish mass with patches of blackish discoloration protruding outside the vulva. Uterine fundus could not be palpated on per abdominal examination. Emergent pelvic ultrasound failed to demonstrate the presence of uterus in the pelvic cavity. These constellations of findings were consistent with the diagnosis of complete uterine inversion. Patient was resuscitated with transfusion of two units of blood and four units of fresh frozen plasma. Uterine tocolytic (magnesium sulphate $4 \mathrm{~g}$ i.v.) was given over 20 minutes to allow uterine relaxation. Manual repositioning of the uterus attempted under general anesthesia was unsuccessful. Thereafter, the decision to perform the Haultain's repair was taken. Intra-operatively a constriction ring was identified. The surgical release of the constriction ring permitted successful uterine reposition. Postoperatively the patient was hemodynamically stable (BP 103/69 mm Hg, pulse $100 /$ minute). Postoperative period was uneventful and the patient was discharged on $10^{\text {th }}$ post operative day. 


\section{DISCUSSION}

Almost all cases of uterine inversion are due to puerperal inversion. Rarely non-puerperal uterine inversion is seen often in association with leiomyomas, uterine sarcomas and endometrial carcinoma. ${ }^{1,2}$ The puerperal uterine inversion is a rare complication of the third stage of labor, defined as the turning of the uterus inside out. The reported incidence of uterine inversion varies widely from 1 in 1584 deliveries to 1 in 20,000 deliveries. ${ }^{3}$ Factors associated with uterine inversion include short umbilical cord, excessive traction on the umbilical cord, fundal implantation of the placenta, antepartum use of magnesium sulphate, administration of oxytocin, umbilical cord traction with vigorous fundal pressure, especially in cases of a fundal placenta, rapid and long labour, and previous uterine inversion. ${ }^{4-6}$ It is also more frequent in primipara and in women previously delivered by caesarean section. The diagnosis of the puerperal uterine inversion is mainly clinical. It most often presents with symptom triad of postpartum hemorrhage, pelvic pain and cardiovascular collapse. The classical clinical presentations include acute uterine inversion within 24 hours of delivery, subacute uterine inversion between 24 hours to $30^{\text {th }}$ day postpartum and chronic uterine inversion after more than 30 days post delivery. ${ }^{7}$ The absence of uterine fundus on per abdominal palpation and inability to visualize or palpate cervix on per vaginal examination suggest uterine inversion. ${ }^{8}$ The severity of uterine inversion has been be classified into four groups: $1^{\text {st }}$ degree: fundus inverted to the level of cervix; $2^{\text {nd }}$ degree: fundus inverted below the cervix but not to the introitus; $3^{\text {rd }}$ degree: fundus inverted to the introitus; and $4^{\text {th }}$ degree: complete uterine inversion associated with vaginal inversion. ${ }^{10}$

Treatment of acute uterine inversion involves immediate resuscitation, antibiotic therapy and uterine repositioning. Uterine repositioning can be achieved non-surgically by manual repositioning of the uterine fundus or hydrostatic reduction (O'sullivan method). ${ }^{11}$ Failure of non-surgical uterine repositioning requires surgical repositioning or hysterectomy. Surgical repositioning can be performed using Spinelli technique (vaginal operative repositioning after incising the cervical constriction ring vaginally), abdominal Huntington's technique (progressive upward traction on round ligament with simultaneous upward pressure transvaginally), and Haultain`s procedure (cervical ring is posteriorly incised to facilitate uterine replacement by Huntington method). ${ }^{12}$ Tocolytics are used to achieve uterine relaxation before reduction is attempted. Drugs that have been successfully used to aid uterine relaxation include magnesium sulphate, glyceryl trinitrate, beta adrenergic agonists (terbutaline, ritodrine) and amyl nitrite. Glyceryl trinitrate offers advantages over other agents because of its rapid onset and reduced maternal tachycardia. ${ }^{13}$ Hysterectomy is preferred in cases of gangrenous uterus or uncontrolled hemorrhage. We performed Haultain's repair in our case as manual repositioning under general anesthesia was unsuccessful.

\section{CONCLUSION}

Uterine inversion is a rare life threatening complication of vaginal delivery. If left unrecognized, it can result in severe life threatening hemorrhage, shock, and maternal death. Active management of third stage of labor and early recognition of the uterine inversion could significantly reduce the incidence and complications of uterine inversion.

\section{REFERENCES}

1. Oguri H, Maeda N, Yamamoto Y, Wakatsuki A, Fukaya T. Non-puerperal uterine inversion associated with endometrial carcinoma-A case report. Gynecologic Oncology. 2005;97:973-5.

2. Cormio G, Loizzi V, Nardelli C, Fattizzi N, Selvaggi L; Non-puerperal uterine inversion due to uterine sarcoma. Gynecol Obstet Invest. 2006;61(3):171-3.

3. Hussain M, Jabeen $\mathrm{T}$, Liaquat $\mathrm{N}$ et al. Acute puerperal uterine inversion. J Coll Physicians Surg Pak 2004;14(4):215-7.

4. Parikshit DT, Niranjan MM, Nandanwar YS. Pregnancy outcome after operative correction of puerperal uterine inversion. Arch Gynecol Obstet. 2004 Mar;269(3):214-6.

5. Agarwal S, Minocha B, Dewan R. Uterine inversion and concomitant perforation following manual removal of placenta. Int J Gynecol Obstet 2005;88:144-5.

6. Beringer R M, Patteril M. Puerperal uterine inversion and shock. Br J Anaesth 2004;92:439-41.

7. Livingston SL, Booker C, Kramer P, Dodson WC. Chronic uterine inversion at 14 weeks postpartum. Obstet Gynecol. 2007 Feb;109(2 Pt2):555-7.

8. Obora VO, Akinola SE, Apantaku BD. Surgical management of subacute puerperal uterine inversion. International Journal of Gynecology and Obstetrics 2006;94:126-7.

9. Coates T. Midwifery and obstetric emergencies. In: Fraser DM, MA C, editors. Myles Textbook for Midwives. 15th ed. London: Churchill Livingstone; 2009. p. 625-47.

10. O`Sullivan J. Acute inversion of uterus. BMJ 1945;2:282-3.

11. Wendel PJ, Cox SM. Emergent Obstetric management of uterine inversion. Obstet Gynecol Clin North Am 1995;22:261-74.

12. Riley E T, Flanagan B, Cohen S E, Chitkara U. Intravenous nitroglycerin: a potent uterine relaxant for emergency obstetric procedures. Review of literature and report of three cases. Int $\mathrm{J}$ Obstet Anesth 1996;5:264-8.

13. Dufour P, Vinatier D, Puech F. The use of intraveinous nitoglycerin for cervico-uterine relaxation: a review of literature. Arch Gynecol Obstet 1997;261:3-7.

DOI: 10.5455/2320-1770.ijrcog20130934

Cite this article as: Sinha M, Gupta R, Gupta P,

Tiwari A. A rare case of subacute uterine inversion managed by Haultain's repair. Int J Reprod Contracept Obstet Gynecol 2013;2:425-6. 